\title{
Popular Concepts of Justice and Hybrid Judicial Institutions in Ghana
}

\author{
Richard C. Crook, Kojo P. Asante and Victor K. Brobbey
}

\begin{abstract}
The provision of effective, legitimate and accessible justice is one of the most fundamental public goods expected from a well-governed state. In this article, we compare the legitimacy of three state or state-supported Ghanaian dispute settlement institutions: the magistrate's courts, the Commission on Human Rights and Administrative Justice (CHRAJ) and the land dispute committees of the neo-traditional Customary Land Secretariats (CLSs). It was found that popular beliefs and expectations are predominantly focused on the notion that justice requires a 'balanced process for establishing the truth', and that the procedures, codes and remedies used by the magistrate's courts and the CHRAJ were more congruent with these beliefs than those of the CLSs. The findings challenge stereotypes of popular and traditional justice as being primarily about reconciliation or restoration of communal harmony, and suggest that state institutions should be supported in their current development of hybrid and informal kinds of dispute settlement.
\end{abstract}

\begin{abstract}
1 Introduction
The provision of effective, legitimate, and accessible justice through judicial institutions and more generally through the 'rule of law' is probably one of the most fundamental of all public goods expected from a well-governed state. By 'rule of law' we mean more than just the current neoliberal conception of a legal system which protects private property and facilitates the market economy. Rule of law refers to the provision of a justice system which sustains the security of all citizens, particularly the most vulnerable, protects against the exercise of arbitrary power by the state or the powerful, and provides for the public regulation of civil disputes in ways which are trusted. In short, the degree of public trust in and the legitimacy of public judicial institutions directly underpins the legitimacy and trustworthiness of the state itself.
\end{abstract}

The 'local justice' research stream of the Africa Power and Politics Programme (APPP) was developed to undertake empirical investigation into what kinds of state or state-supported justice institutions in African states might provide such legitimate, effective and accessible dispute resolution - and if so, what might explain any positive outcomes.
Currently, the legal systems and courts of most African countries are widely condemned as inaccessible to ordinary citizens because of their formality, alien procedures and concepts derived from their colonial origins, corruption and inefficiency. In Anglophone common law countries in particular, there is a deep crisis caused by overload and backlog of cases. In recent years, however, many African states have attempted to address these crises of the public legal system through reform of judicial institutions, particularly at the local level. The search for alternatives has included 'popular justice', revival of 'traditional' forms of dispute settlement and chiefs' tribunals applying customary law, and various forms of Alternative Dispute Resolution (ADR), ranging from court-attached ADR to state support for paralegals, non-governmental organisations (NGOs) and other agencies.

In this article, we compare three different kinds of local dispute settlement institution (DSI) in Ghana: formal state courts, a new state-sponsored ADR service and a land disputes resolution system based on the traditional chieftaincy authorities. ${ }^{1}$

The district or 'magistrate's' courts are the lowest-level courts of first instance operating with a single, legally qualified or trained judge 
and applying both civil and criminal formal state law (which in Ghana includes customary law). They have been in existence for over 150 years, since the time of the Gold Coast colony. Since 2005, they have also become venues for the Judicial Service's national 'Court-connected ADR' programme, using paid paralegal mediators. The official purpose of the ADR programme is to tackle the enormous backlog of pending cases in the state system and improve accessibility for the 'poor and vulnerable'.

The Commission on Human Rights and Administrative Justice (CHRAJ) was established under the 1992 Constitution and its autonomy and independence are constitutionally guaranteed. Its principal mandate is to investigate abuses of power and maladministration, whether by government or other agencies, which infringe citizens' human rights as guaranteed by the Constitution. It is, however, unusual compared to other national human rights commissions, in that it has a network of district offices in around 110 of Ghana's 170 districts. These district offices offer a free mediation or ADR service to complainants. The service has attracted increasing numbers of individual citizens seeking resolution of disputes, ranging from matrimonial and family disputes to inheritance, land and property cases, landlord-tenant relations and employer-employee cases.

The Customary Land Secretariats (CLSs) are new 'hybrid' institutions set up by the Ministry of Lands from 2003 onwards. They are still at a pilot stage - only 39 have been established, of which only ten have existed since 2005 . They are administered by chiefs and staff employed by the Traditional Councils, but their function is a modern one: to record and demarcate the full range of local lands held under customary tenures (80 per cent of all land in Ghana) and to record and formalise the sale, leasing or other allocations of land under the control of customary authorities - chiefs, family heads or 'land priests'. The CLSs are mandated to deal with disputes which arise - particularly over demarcation and definition of rights - by setting up 'land dispute resolution committees' called Land Management Committees. These bring together representatives of the customary authority with local government and community interests. The Committees are led by the chiefs and basically follow customary procedures and conventions relating to land, although officially they have been enjoined to offer ADR.

The main aim of the research was to assess and explain the extent to which these dispute settlement institutions (DSIs) were providing public dispute settlement, which was 'legitimate, accessible and effective'. The empirical focus was on civil cases, consisting mainly of land disputes, inheritance and property, but also including family matters, debt, landlord-tenant relations and 'defamation'. All three of the DSIs dealt with land or inheritance cases (unofficially and only infrequently in the case of CHRAJ), while the CHRAJ and magistrate's courts covered all of the other matters.

In this article, we are concerned particularly with the performance of the three DSIs on the legitimacy dimension. Legitimacy was defined and operationalised as the extent to which the codes of justice, procedures and remedies offered by the three DSIs were congruent with the beliefs, expectations and demands of both the general public and litigants who used them. Clearly, different kinds of cases need different remedies, and in a context of legal pluralism the kinds of remedies offered by various DSIs will have an influence on which ones are used by disputants (often many through the life of a single case). But the legitimacy of a particular DSI was judged by whether it matched up to what the litigants were seeking - their expectations and sense of justice - regardless of the kind of case.

We argue that the procedures and codes of the magistrate's courts and the CHRAJ are on the whole more congruent with popular values about fairness and just resolution of disputes than those of the CLSs. These findings challenge the conventional stereotype that the majority of ordinary people believe in and prefer 'traditional' modes of dispute settlement, which are assumed to emphasise communal harmony and restorative justice.

\section{Legitimacy, 'cultural repertoires' and local concepts of justice}

One of the main hypotheses of the APPP is the proposition that public institutions are more likely to be effective at providing public goods if they are 'locally anchored' in ways of doing things which draw on established forms of moral obligation and collective action, or available 'cultural repertoires' (Booth 2010; Kelsall 2009). ${ }^{2}$ 


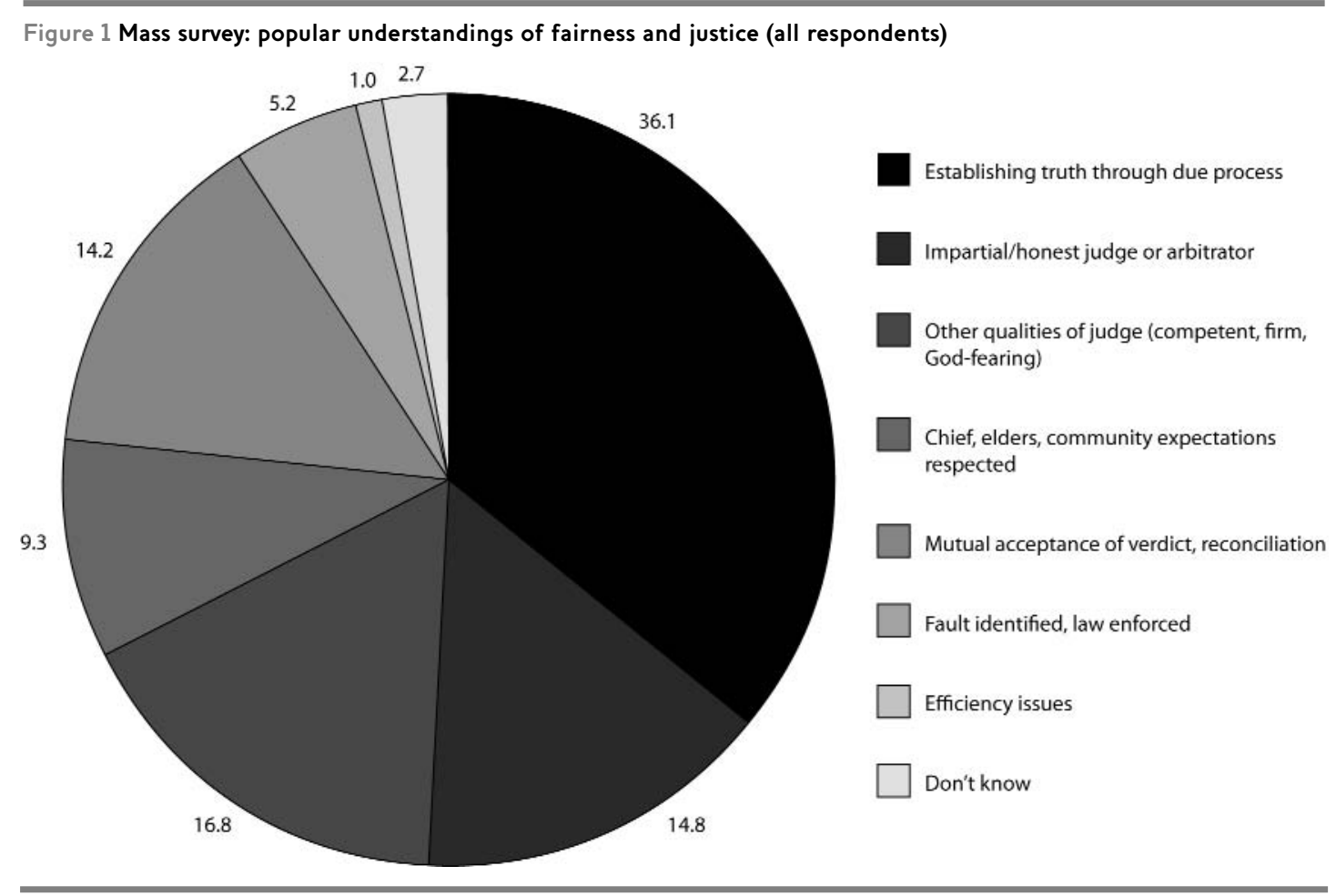

Because of the ideological baggage associated with the concept of 'tradition' in Africa, and the confusions surrounding its historical transformations during and since colonial rule, APPP does not make any assumptions about the character of the available cultural repertoires; they may well be historic, or reinventions using historic referents, and may also be contemporary creations of post-colonial society (Olivier de Sardan 2008). They therefore need to be established empirically in each local context, not assumed, as is often the case with stereotypes of African tradition and popular culture.

Legitimacy has been defined as the belief by citizens in the 'rightfulness' of an authority, in this case a state-supported legal institution (Poggi 1978: 101-2; Crook 1987). In other words, it is a moralisation of legal - and hence political - authority. As Merry has noted, 'disputing is cultural behaviour... [it is about] ways of doing things that seem right, normal or fair...' (Merry 1987: 2063). In constructing a picture of local beliefs and expectations about dispute settlement and justice we therefore collected data on:

1 What did users of the DSIs (parties to disputes) and local communities actually seek from the state and its judicial institutions? What theories did people hold about what is 'just' or correct and fair? What did they value? What were their experiences of these DSIs, either directly or indirectly?

2 How did these local understandings correspond to the way in which the various DSIs were working? What codes, procedures and remedies were actually used by the various DSIs?

The data were collected using a variety of methods: two case study districts were selected, one in peri-urban Accra, and the other a cocoagrowing rural district of Brong-Ahafo Region. ${ }^{3}$ In each, a representative sample survey of popular opinion was conducted, together with interviews with litigants in the three DSIs over a five-month period using a structured questionnaire, and anthropological observation of the DSIs in action. The main purpose of the observation was to provide information on what kinds of legal or moral codes and procedures were actually used by the various courts or tribunals. It also provided useful insights into the relationships among litigants, judges and the public attending the hearings. 


\begin{tabular}{lllll}
\hline \multicolumn{1}{l}{ Table 1 Popular understandings of justice, by type of respondent (\%) } \\
\hline & Subset 1 & Subset 2 & Subset 3 & All \\
\hline Establishing truth through due process & 44.7 & 31.6 & 33.5 & 36.1 \\
Impartial/honest judge or arbitrator & 15.5 & 12.7 & 15.4 & 14.8 \\
Subtotal 1 + 2 & 60.2 & 44.3 & 48.9 & 50.9 \\
Other qualities of judge (competent, firm, God-fearing) & 5.6 & 1.3 & 35.3 & 16.8 \\
Chief, elders involved, community expectations respected & 0.0 & 13.4 & 9.4 & 9.3 \\
Mutual acceptance of verdict, reconciliation & 14.9 & 28.0 & 0.0 & 14.2 \\
Fault identified, law enforced & 5.6 & 10.1 & 0.0 & 5.2 \\
Efficiency issues (delay, cost, etc.) & 3.7 & 0.7 & 0.0 & 1.0 \\
Don't know & 0.0 & 0.0 & 6.3 & 2.7 \\
\hline
\end{tabular}

3 Popular ideas: evidence of the mass survey

The survey of popular opinion on justice and dispute settlement interviewed 800 respondents selected randomly from the two case study districts, using a multi-stage, stratified area sample with random selection of households and random selection of individuals within households. ${ }^{4}$ The questions sought to avoid expression of hypothetical opinions without an action context. It was nevertheless anticipated that only a minority of such a random popular sample would have actually been parties to a formal 'case' or dispute. Three main groups emerged during the interviews:

1 Subset 1: those who had actually experienced a case (20.1 per cent).

2 Subset 2: those who had witnessed a dispute settlement in their community (38.4 per cent).

3 Subset 3: those who said they had neither been involved in nor witnessed a dispute settlement (41.4 per cent).

Respondents in Subsets 1 and 2 were asked to explain why they thought a case they had been party to or had witnessed was handled fairly or unfairly. Those in Subset 3 were asked a more hypothetical question: 'If you ever got involved in a case, what are the most important things about a dispute settlement institution which would make you trust them to give a fair settlement of your case?'. The questions were open-ended and then post-coded for the principal meaning of the answer given.

\subsection{Concepts of fairness and justice}

Overall, the largest single group of respondents across all subsets (36.1 per cent) explained their answer on fairness by emphasising the importance of the truth ('the true facts') being established through what could be termed a 'balanced process' - specified as both parties being allowed to speak freely and make their case to the judge (Figure 1 and Table 1).

The second most important set of ideas related to the qualities required of a judge, particularly impartiality (expressed variously as 'not biased', 'honest', 'respects the truth', 'listens to both sides') and other qualities such as 'competence', 'reputation', 'experience', or being 'God-fearing'. The idea of an 'impartial judge', it may be argued, is closely linked to the idea of a balanced process, and this combination accounted for over half of all responses. Adding the other 'wise qualities' of a judge brings the total to 68 per cent of all responses.

It may therefore be argued that the notion that justice requires a 'balanced process for establishing the true facts' was very widespread in the general population of the districts surveyed, regardless of people's personal experiences - although it was clearly much more important to those who had actually been party to a case. (Of the latter group, 33 per cent had been involved in a state court, and only 25 per cent in a traditional chief's court, with the remainder having used various kinds of informal dispute settlement drawn from community or family.)

A substantial minority of respondents expressed other views but these were more fragmented and 


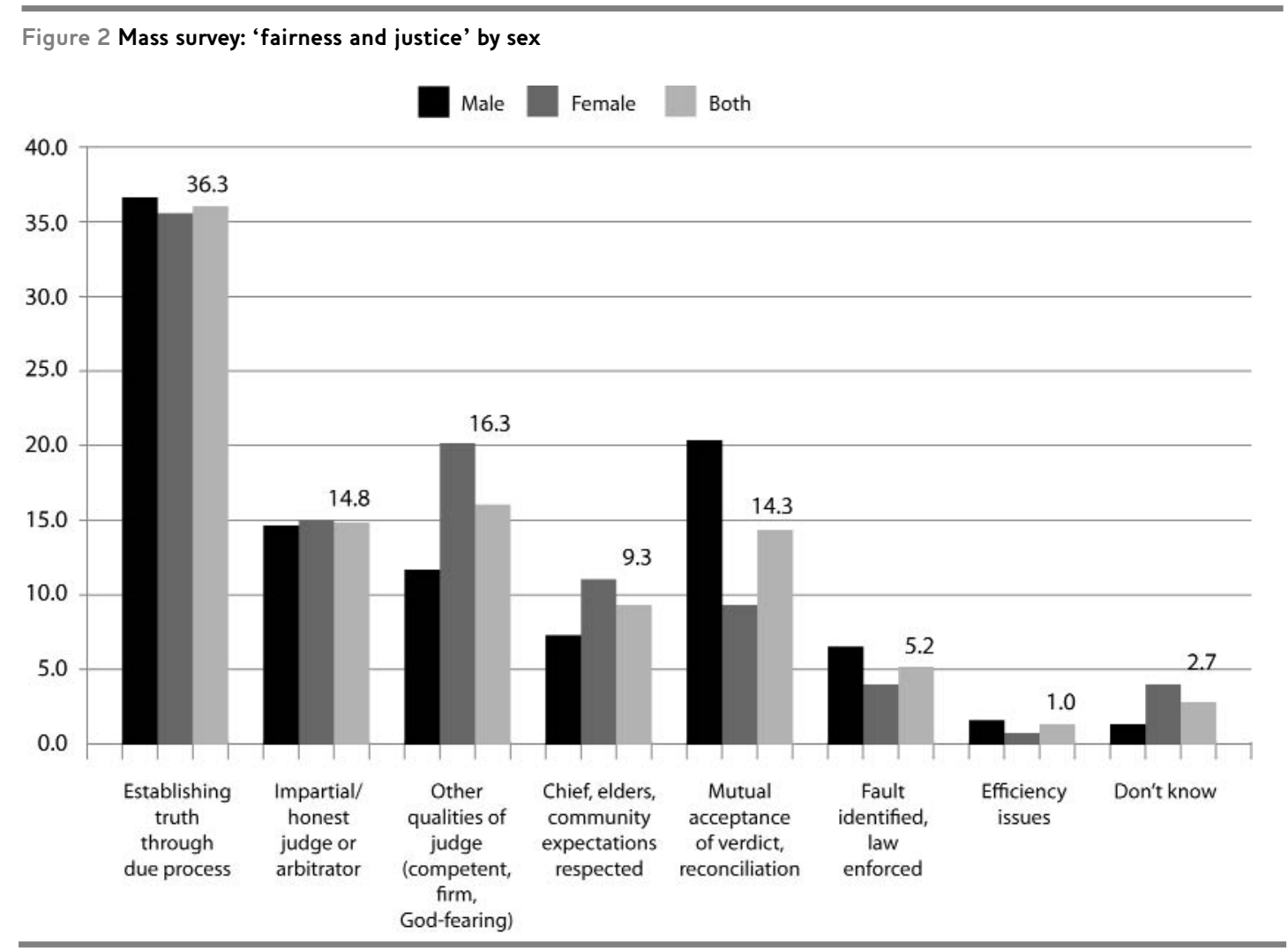

therefore formed a number of minority positions which could not collectively be seen as a coherent alternative to the 'balanced process' concept. For instance, the third most important group talked about the importance of disputants coming to 'understand each other' better and both accepting the result. This is an idea which was also echoed by litigants in the three DSIs and can be related to a general longing on the part of disputants to attribute a moral quality to any settlement - a sense that hostilities need to be buried. But it is noteworthy that the 'communitarian' view and a belief in the necessity for involvement of chiefly authorities was expressed by only a small minority.

To what extent did social differences such as gender, age, educational level or occupation have an influence on people's views about justice and fairness? Surprisingly, there were few significant differences apart from gender (Figure 2). The age of respondents had virtually no impact on what kind of view they were likely to hold - there was particularly strong consistency on the 'balanced process' value - and levels of education seemed to make little difference either, except that respondents with a post-secondary education (a very small proportion of the sample) were much more likely to suggest that qualities of the judge such as competence and reputation were important. On occupation, few differences of any significance could be discerned.

But women were much less likely to emphasise the importance of reconciliation or mutual acceptance than men - an indication perhaps of the extent to which getting involved in a public dispute is a last resort for women, making them more determined to pursue a remedy to the bitter end. And women were slightly more likely to argue that a judge should be competent and 'God-fearing', and that community expectations were important. But these were not major differences which could give rise to any strong sociological or policy finding on the significance of gender in local cultures of justice and dispute settlement.

\section{The litigants' experiences of dispute settlement}

To what extent were the views expressed in the representative popular survey shared by litigants who were involved in a case before one of the selected DSIs? Our evidence is drawn from purposive surveys of litigants using a structured 


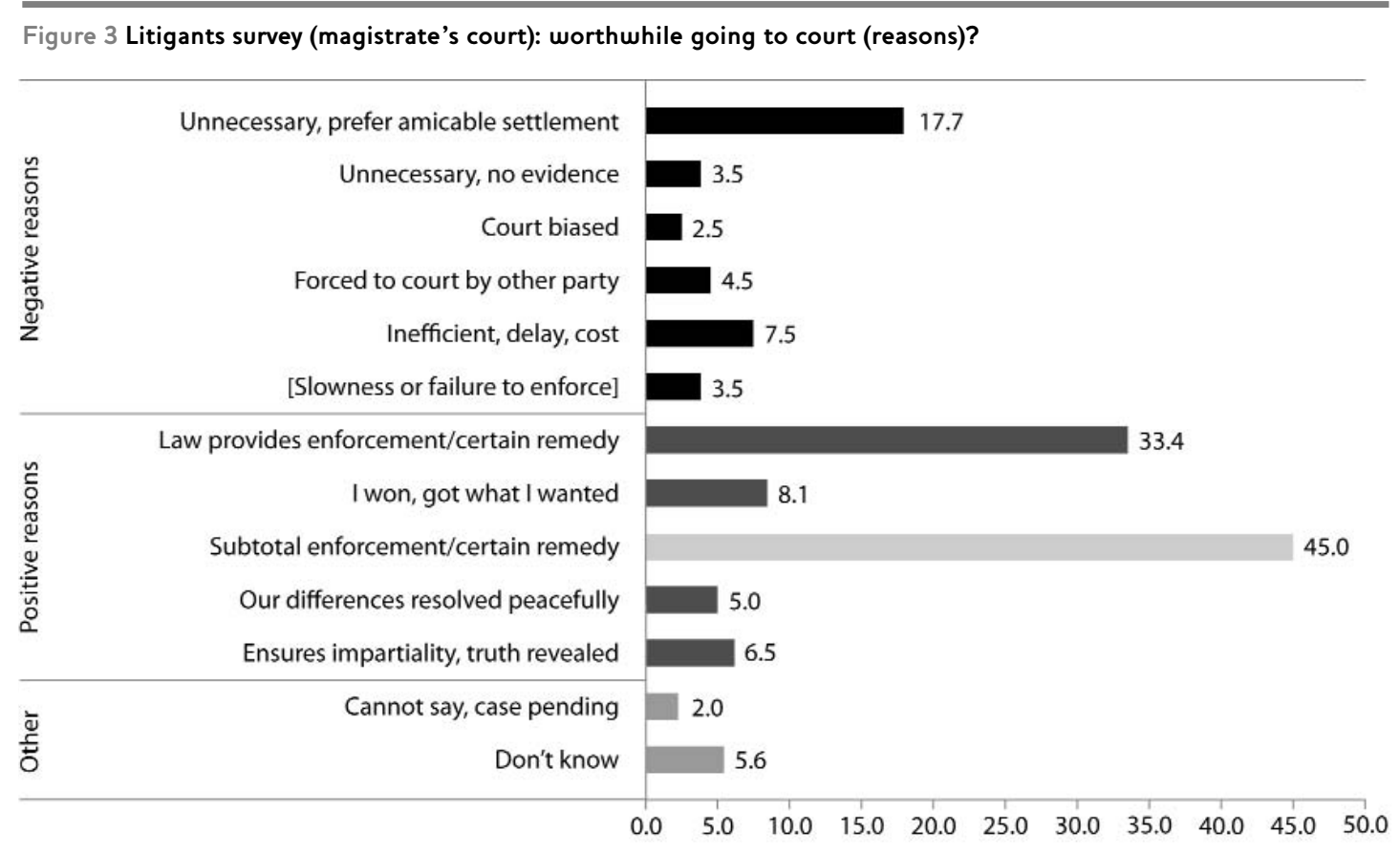

questionnaire: for the magistrate's courts, 199 respondents were interviewed over a five- to sixmonth period focusing on those with land or inheritance, property and breach of contract cases, with a small selection of others involved in matrimonial, theft and defamation cases.

Compared to the general population of the two districts, the litigants (slightly more men than women) were an older group (48.3 per cent aged over 40), and were much more highly educated than the average population ( 36.2 per cent had a secondary or post-secondary education), while only 9.5 per cent were illiterate. ${ }^{5}$

A total of 48 respondents who had disputes being heard by the CHRAJ and 40 with cases under the CLSs were interviewed in the two districts over a six-month period. The CHRAJ sample revealed a much younger profile compared to the magistrate's courts and the CLSs: over 60 per cent were under 40 years of age. Their modal level of education was also lower than the other two DSIs - 52 per cent Junior Secondary or the old Middle School Leaving Certificate. District case statistics show that the majority of complainants going to CHRAJ were women bringing cases against men for maintenance of children, disagreement over custody of children, breaches of promise to marry, and maintenance after separation or divorce, often mixed with accusations of domestic violence and abuse.
The majority of the litigants in the CLS were older men (70 per cent), with generally quite high levels of education (47 per cent with secondary or post-secondary levels).

In a context of legal pluralism, the reasons for choosing a particular DSI give a powerful indication of what people value in dispute settlement. A common assumption is that most ordinary people prefer informal or traditional DSIs if they are involved in a dispute, and indeed when respondents in the mass survey were asked a hypothetical question about who they would 'trust a lot' if they had a dispute to settle, over 70 per cent said they would trust their village chief, a family head or their religious leader. But actual behaviour was somewhat different.

For 53.3 per cent of the litigants, the magistrate's court was their first choice, showing the powerful attraction of the kinds of legal remedies offered by these courts. Of those who had tried another DSI first, 57 per cent had used family elders or community elders, and only 9.1 per cent a chief's traditional court - much fewer than the number who had used Unit Committee or District Assembly officials or other bodies (12.5 per cent). The main reasons given for choosing the court and for thinking that bringing the case had been worthwhile overall - focused on the prospect of enforcement and certain remedies, together with 


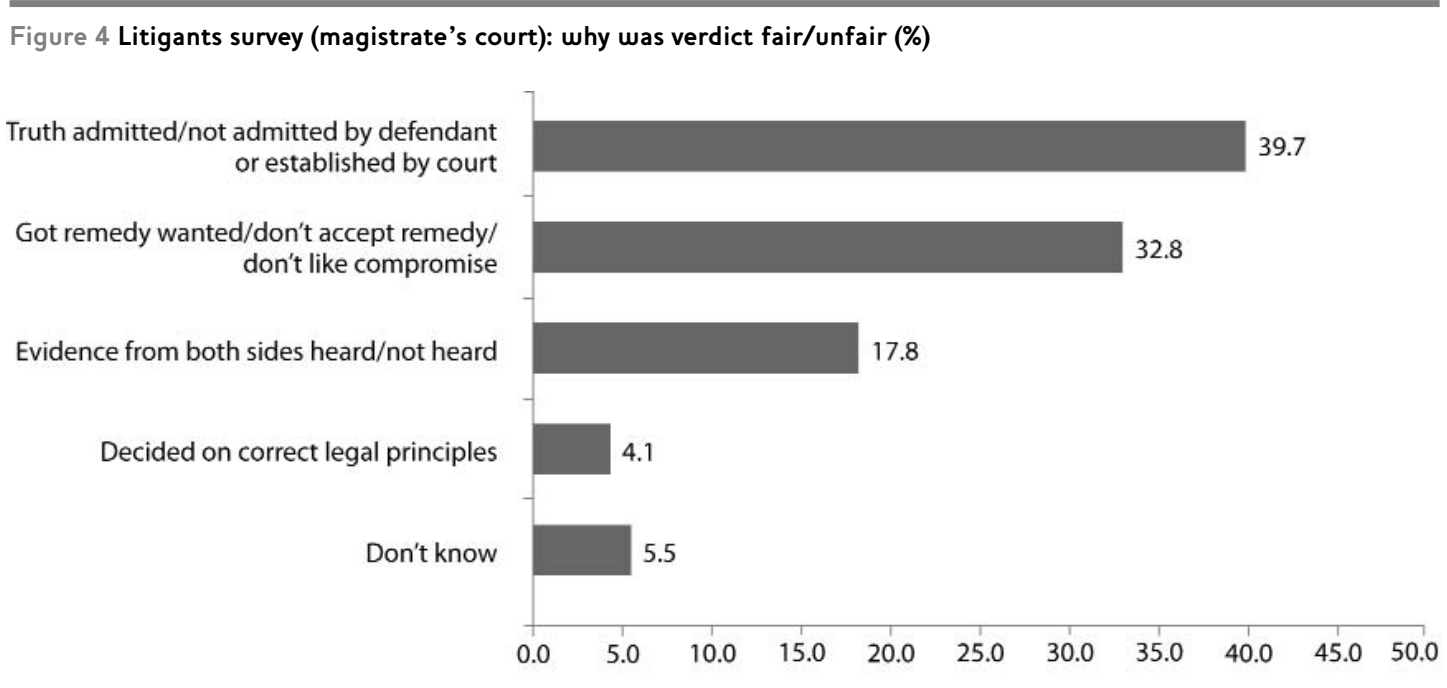

a procedure which would be impartial and bring out the truth. Some said that they wanted to 'change the behaviour' of the other party; others cited the failure of amicable settlement to produce a result (Figure 3).

The choice of CHRAJ seems to have been mainly determined by practical considerations relating to its location, and the fact that its services were free, although one-fifth of respondents mentioned its 'good reputation'. (The popular survey showed that the CHRAJ was not that well known outside the main district towns). Some 60 per cent of the litigants in the CLSs said that they saw it as the most appropriate in terms of its jurisdiction (customary land), and its reputation or competence.

Litigants' ideas of fairness were also revealed by asking those whose case had been settled, whether they thought the verdict was fair/unfair, and to give reasons for their response. In the magistrate's courts, of those respondents whose case had been settled (37 per cent of the total), 89 per cent felt the verdict was very or somewhat fair. The most cited reason for saying the verdict was fair or unfair focused on the allocation and acceptance of fault or liability: 40 per cent argued that what really mattered was that the 'truth had come out' and that the defendant (in some cases themselves) had - or had not accepted the truth of the accusations or problems raised. Related to this, 17.8 per cent said that the fairness or unfairness of the verdict was based on whether both sides had properly been heard. Thus nearly 60 per cent saw fairness as either getting the truth to come out and be accepted by both parties, or (a related idea) the fact that both sides had been properly heard (Figure 4). None made any mention of the idea that the verdict was good because a compromise had been reached.

In the GHRAJ mediations, 61 per cent felt that the agreement was fair and they were satisfied with the result; but one interesting aspect was that a small group was dissatisfied even though they acknowledged it was fair. Closer analysis revealed that defendants were in fact more likely to be satisfied that the verdict was fair and plaintiffs were more likely to say it was fair but they were dissatisfied. This shows very clearly the impact of a process which emphasises compromise - people can emerge feeling that they have not really got all that they wanted or felt entitled to, while the defendants feel that they have done a good deal.

In fact when discussing their cases, the CHRAJ respondents did not really emphasise compromise as the core value; the largest group (42 per cent) saw the verdict as being a determination of facts (bringing out the truth) or even an application of 'the law'. But another significant group saw the process as having a moral dimension - namely that it was about confirming duties to care for or provide for children, particularly in maintenance cases. This shows how people who sought an ADR-type settlement through the CHRAJ were primarily concerned to get the person who they felt had wronged them to 'do the right thing'. 
The most interesting theme to emerge from discussions on the CLS verdicts was the strong emphasis which the litigants put on 'bringing out the true facts' (74 per cent overall); nearly half of those interviewed said that the verdict revolved around formal documentary evidence. But only 52 per cent were both satisfied with the verdict and felt it was 'fair'. There was little or no interest in 'compromise' or reconciliation. Indeed, in many cases the 'winners' were observed being doused in white powder by their entourage, a traditional way of celebrating victory. So they were clearly very interested in establishing fault.

\section{Congruence between popular concepts of justice and the procedures of the three DSIs 5.1 Summary of local values}

The evidence of both the mass survey and the interviews with litigants shows that, whatever the kind of case, what people seem to value most strongly is a judge or arbitrator perceived to be impartial and competent, who can ensure that the true facts come out and the disputing parties are given a fair chance to present their stories. In short, the local concept of 'fairness' is identified with the idea of a 'balanced process'. This does not mean that people necessarily accept the English common law adversarial view of 'due process'. Ghanaians want to see both parties to a case given an equal hearing, but do not necessarily see justice as emerging from a contest, like a debating society competition.

An additional important idea, emerging especially from those who were using the magistrate's courts or who had previously had a personal experience of a case, is that there should be a mutual acceptance by both parties that the verdict or outcome is indeed truthful and that fault, if established, has been accepted. In other words, there is a desire to give the judicial process a moral character. This is not the same as 'compromise', but more a hope that further hostility can be avoided.

The remedies which people seek are, however, clearly linked to the kind of case and its history, and this has a powerful influence on the kinds of DSIs which people use. Thus many disputants had initially used informal, non-state DSIs (family, respected community leaders, village chiefs, religious or political leaders), perhaps hoping for an amicable private settlement. But with land cases, as well as intra-family property disputes or contract and debt cases, the level of hostility and even violence is often such that this kind of dispute resolution fails. The CHRAJ offers a real alternative when what people are really seeking is compensation, but compromise is not always what people want nor is it even in their best interests.

Thus, by the time the disputants arrive in court, plaintiffs are resolutely seeking a clear and enforceable remedy which will give a declaration of title, or enforce specific actions on the defendants, to pay what is owed or pay damages. (The magistrate's courts were even dealing routinely with 'defamation' cases, often a code for witchcraft accusations.) The strong interest in establishing fault and certainty of enforcement is vividly confirmed by the extraordinarily low rates of 'out of court' settlement in Ghana (Crook et al. 2007).

\subsection{The legitimacy of the magistrate's courts}

Although the magistrate's courts retain the formal atmosphere of a state court in which strict order is kept, hybridity is clearly emerging in the use of various kinds of informal, non-legal procedures. Local languages are used in the vast majority of cases, with English only used by the judge to record his or her notes, and the judges frequently adopt inquisitorial or even conversational strategies in order to facilitate the disclosure of facts by parties and witnesses. They give advice and suggest ways of settling. This is particularly the case when they are sitting as a Family Tribunal, and they are now routinely encouraging resort to ADR.

The litigants in the magistrate's courts had a generally positive view of the trial process; when asked to comment (in an open-ended question) on how they thought the judge had conducted the hearings, the overwhelming majority (72.2 per cent) made positive comments, focusing on the extent to which the judge seemed to behave as a balanced, honest or helpful person.

The codes or concepts of justice underlying the work of the judges in the magistrate's courts seemed to derive quite strongly from their professional self identity, based on their common law training and socialisation into the traditions of the Ghanaian judiciary. They proclaimed their belief in the classic common law view of justice as 'due process' (Dowrick 1961). But they also talked the language of rights - ironically, more so than 
the CHRAJ officials - saying that compromise cannot be allowed to prevent people getting their legal rights.

In practice, these courts used a variety of laws and principles, not just common law and statute. They applied established customary laws where the judge thought they were appropriate, for example Akan matrilineal inheritance for land, and in some observed cases used Ghanaian 'cultural principles', such as respect for the elderly. In some of the court-attached ADR mediations the mediators were even observed invoking evangelical Christian ideas, which are now very widespread among the general population.

The values of justice and the procedures used in the magistrate's courts seem, therefore, to correspond very closely to the dominant popular views of justice and fairness, and they offer the kinds of enforceable remedies sought by litigants. The only difference is that ordinary people put less of a premium on the adversarial process itself, seeing justice more as a genuine search for the truth.

\subsection{The legitimacy of the CHRAJ mediation service}

The congruence of the CHRAJ mediations with popular understandings of justice is very strong: its district officers, trained in ADR and personally committed to a 'human rights' code of ethics, do provide an impartial arbitration which does give all parties a real (and unrushed) opportunity to put their case in a friendly, noncoercive atmosphere. The CHRAJ mediators rarely made use of either customary or legal principles, particularly in relation to marriage or sexual relations, but focused intensively on reaching agreed compromises often based on monetary compensation and local conceptions of morality. Their service is especially attuned to the needs of poor and vulnerable people, particularly young women who would normally be afraid to take these kinds of cases to court. Overall, 71 per cent of the litigants felt that the CHRAJ was the 'best way of settling disputes'.

A few issues can be raised about the remedies they offer. Their settlements were generally respected as they have the authority which comes from being a constitutionally protected and independent state institution, and they facilitated compensation payments through their offices. But they cannot enforce the agreements of these mediations, and whether they would automatically be upheld by a court has not been tested. A problem arising from the CHRAJ procedures is that the emphasis on compromise and agreement above all else can still result in pressure on weaker parties to accept settlements which do not really serve their best interests or may prevent them from obtaining their full legal rights (Nader 2001).

\subsection{The legitimacy of the CLSs and Land and Chieftaincy Disputes Resolution Committee}

Although the CLSs are supposed to be based on the existing, formally constituted Traditional Authorities, they are still 'new' institutions and little known to the public, partly because only small numbers of pilot GLSs have as yet been set up and even fewer are fully operational. The mixed District Assembly/Chieftaincy Committees are even less well known and are the product of initiatives taken in particular districts on a rather random basis.

Official policy for the CLSs is that they should provide an ADR-type service for land disputes, promoting 'win-win' settlements based on compromise and restorative justice. In practice, the CLS panels seemed predominantly concerned to establish the 'facts of the case', resorting to documentary evidence of land claims and local histories. Curiously, rules of judicially established customary law, or other land laws were rarely applied, and the communal dimension was acknowledged mainly through a concern with the rights of Stools, and consultation with local opinion leaders and other chiefs on the broader aspects and merits of the case. The strong emphasis of many panels was in fact on establishing who was the rightful winner, arguing that 'there is only one truth'. This was demonstrated in the practice of making only the losing party forfeit his 'advance against costs' to the CLS panel.

The procedures themselves, although conducted in local languages, were very formal, combining elements drawn from the state court system (e.g. written summons in English) with the formal rituals and protocols of the traditional chieftaincy. Many of the latter are quite intimidating to ordinary citizens, especially women and migrant farmers. Traditional hierarchies were reproduced quite strongly in the court format, for example 'subjects' had to remove their sandals and stand throughout. 
The justice offered by the CLSs is not, therefore, very congruent with popular values except insofar as they offer a clear win/lose verdict to litigants who have similar goals to those who use the magistrate's court. But their formality, hierarchical character and embeddedness in the local land-holding power structures suggest that they will not offer a genuinely balanced or accessible process - even if individual chiefs who are respected as individuals could in fact adjudicate wisely. Only 47.5 per cent of litigants felt the CLS was the 'best way of settling disputes' - the lowest of the three DSIs.

\section{Conclusions}

Our empirical data provide some evidence on the relationship between, on the one hand, what ordinary people and the users of the selected DSIs actually think about justice and dispute settlement, and, on the other hand, what these institutions are offering in practice. Comparison of the three DSIs shows that the magistrate's courts were highly congruent with popular values and expectations, and offered the majority of litigants what they were seeking. The CHRAJ ADR mediations were also clearly attuned to important sets of beliefs and needs, especially for vulnerable people such as the poor and young women who could not afford or were afraid to use, formal courts, and wanted impartial, amicable settlement. The customary-based CLS land dispute committees seemed the least attuned to popular ideas and expectations about how to settle land disputes, catering to a relatively narrow and elite set of clients using very formal traditional procedures.

Two particularly interesting aspects of the findings may be highlighted.

First is the challenge they present to the conventional, indeed stereotypical, picture of popular ideas about justice, long presented in much of the literature which assumes that:

1 the majority of Ghanaians prefer the 'informal' customary justice or dispute settlement institutions as offered by chiefs; and

2 customary or traditional justice means restorative justice and the privileging of social harmony over individual legal rights; and an acceptance that the judge need not be neutral or detached but rather has intimate knowledge of the parties and their families (Allott 1968, cited in PRI 2000: 24-25). ${ }^{6}$

This is not in fact what Ghanaians appear to seek from justice institutions, and these stereotypes of traditional justice are in themselves misleading. ${ }^{7}$ Insofar as the CLSs are offering some contemporary version of a customary court procedure, they will not necessarily emphasise reconciliation; and neither are they plausibly going to offer an ADR-type mediation in which an impartial stranger focuses on balancing the claims of two individuals without the use of unequal power resources. The CLS panels are too embedded in the power relations of local land ownership and social hierarchies to offer this kind of settlement (Crook 2008: 137-9). Their concern is more to establish rightful claims according to customary rules of historical legitimacy, which involve constant renegotiation in the light of changing social group relations (Berry 1997, 2001; Juul and Lund 2002). This means that decisions in practice reflect political relations and inequalities of power (Peters 2002). Ordinary citizens still respect chieftaincy and 'tradition' in Ghana, but they are only likely to resort to a chiefly institution if they are already involved in a set of relationships over land, which suggests that the chief will look on their claim favourably. It is only at the family or very local level that informal modes of traditional dispute settlement may be resorted to when there is still the hope of a fair and amicable settlement.

Second, it is worth emphasising the significance of the positive findings on the magistrate's courts and the CHRAJ. As the litigants' survey shows, these state institutions offer a form of justice and a set of remedies which are highly valued and it is quite mistaken to imagine that so-called 'informal' DSIs could provide a complete alternative; both kinds of institution are needed.

It is true, of course, that the state courts have a crisis of effectiveness; they are unable to cope with the huge and increasing numbers of suits lodged..$^{8}$ In this sense, the magistrate's courts are the victims of their own popularity, but this does not mean they should be abandoned; they rather need reform, resources and new ways of working. Various measures could focus on developing and encouraging the informalities and judicial 
activism already being practised by magistrates. Much of the backlog of cases is caused by constant adjournments occasioned by weaknesses in court administration. Above all, the popular reluctance to consider out-of-court settlement has to be tackled - and this is perhaps a 'cultural' matter, to which ADR is seen as the solution. But ADR will not address this rooted behaviour unless it is implemented in very specific ways. This is where institutions such as the CHRAJ or

\section{Notes}

1 The research was a collaboration between Richard Grook of IDS and Ghana Center for Democratic Development (CDD-Ghana) researchers under the leadership of Professor Gyimah-Boadi, Kojo Asante and Victor Brobbey. We gratefully acknowledge the contributions of other CDD staff, including Daniel Armah-Attoh and Sewor Aikins who worked on the questionnaires and data entry, and Kwabena Aborampah-Mensah (Programme Manager and mass survey supervisor).

2 The term 'cultural repertoire' is taken from Ann Swidler's seminal article (1986).

3 The choice of districts was severely constrained by the need to find ones where there were functioning CLSs alongside the other two justice institutions. Within that constraint the basic comparison was between rural and urban settings.

4 See Crook et al. (2010) for full details of the survey which was carried out by CDD-Ghana using recent graduates from the University of Ghana and Kwame Nkrumah University of Science and Technology, Kumasi, trained by CDD and APPP researchers. Interviews were conducted in the local languages (Twi or Ga) or English depending on what respondents found most comfortable.

5 According to the 2000 Ghana census, 20 per cent of the population aged over 15 in the Accra the Court-attached ADR offer such positive possibilities; they have real congruence with popular values about procedure and impartiality, and offer enforcement of remedies. If their reach could be extended and the legal profession brought on board, they might begin to make an impact. Above all they must satisfy the most basic popular value which seems to emerge from the research; they must ensure that the 'truth comes out'.

Region district were illiterate and 39 per cent in the Brong-Ahafo Region district. The figures for those with a secondary or postsecondary educational level were 25.6 per cent and 11.5 per cent, although this included all those over the age of six, so somewhat overstates the level for the adult population.

6 For a full review of this literature see (PRI 2000: 24-34).

7 Note that over half of litigants in the magistrate's courts had chosen to go straight to that court, and that of those respondents in the mass survey who had experienced a case, only 25 per cent had used a chief's court as against 33 per cent a state court. See Rattray's 1929 account of the procedures in the court of a superior Asante chief for a more authentic picture of customary justice (Rattray 1969: 388).

8 The magistrate's courts nationally dealt with 43,100 civil cases and 49,272 criminal cases in 2007-08, representing clear-up rates of only 40 per cent and 30 per cent, respectively; in our Accra case study court in the same period, 264 civil cases were cleared up (21 per cent of the total pending) and in the Brong-Ahafo court 240 civil cases out of a much lower total, representing a clear-up rate of 47 per cent (Ghana 2008). The CHRAJ office in the Brong-Ahafo district was dealing with 350 mediations a year in 2009 . 


\section{References}

Allott, A.N. (1968) 'African Law', in J.P. Derrett (ed.), An Introduction to Legal Systems, London: Sweet and Maxwell: 131-56

Berry, S. (2001) Chiefs Know Their Boundaries: Essays on Property, Power and the Past in Asante, 1896-1996, Portsmouth, NH: Heinemann

Berry, S. (1997) 'Tomatoes, Land and Hearsay: Property and History in Asante in the Time of Structural Adjustment', World Development 25.8: 1225-41

Booth, D. (2010) Towards a Theory of Local Governance and Public Goods' Provision in SubSaharan Africa, Working Paper 13, London: Africa Power and Politics Programme

Crook, R.C. (2008) 'Customary Justice Institutions and Local Alternative Dispute Resolution: What Kind of Protection Can they Offer to Customary Landholders?', in J.M. Ubink and K.S. Amanor (eds), Contesting Land and Custom in Ghana, Leiden: University Press: Chapter 6

Crook, R.C. (1987) 'Legitimacy, Authority and the Transfer of Power in Ghana', Political Studies 35: 552-72

Crook, R.C.; Asante, K. and Brobbey, V. (2010) Popular Concepts of Justice and Fairness in Ghana: Testing the Legitimacy of New or Hybrid Forms of State Justice, Working Paper 14, London: Africa Power and Politics Programme

Grook, R.C.; Affou, S.; Hammond, D.N.A.; Vanga, A.F. and Yeboah, M.O. (2007) The Law, Legal Institutions and the Protection of Land Rights in Ghana and Côte d'Ivoire: Developing a More Effective and Equitable System, Research Report 58, Brighton: IDS

Dowrick, F.E. (1961) Justice According to the Common Lawyers, London: Butterworths
Ghana, Republic of, Judicial Service (2008) Judicial Service Annual Report 2007-8, Accra: Government Printer

Juul, K. and Lund, C. (eds) (2002) Negotiating Property in Africa, Portsmouth, NH: Heinemann

Kelsall, T. (2009) Game Theoretic Models, Social Mechanisms and Public Goods in Africa: A Methodological Discussion, Discussion Paper 7, London: Africa Power and Politics Programme Merry, S.E. (1987) 'Review: Disputing Without Culture', Harvard Law Review 100.8: 2057-73

Nader, L. (2001) 'The Underside of Conflict Management - In Africa and Elsewhere', IDS Bulletin 32.1: 19-27

Olivier de Sardan, Jean-Pierre (2008) A La Recherche des Norms Pratiques de Gouvernance Réelle en Afrique, Discussion Paper 5, London: Africa Power and Politics Programme, www.institutions-africa.org/filestream/ 20090109-discussion-paper-5-la-recherchedes-norms-pratiques-de-la-gouvernance-r-elleen-afrique-jean-pierre-olivier-de-sardan-d-c2008 (accessed 21 December 2010)

Peters, P.E. (2002) 'The Limits of Negotiability: Security, Equity and Class Formation in African Legal Systems', in K. Juul and C. Lund (eds), Negotiating Property in Africa, Portsmouth, NH: Heinemann: 45-66

Poggi, G. (1978) The Development of the Modern State, London: Hutchinson

PRI (2000) Access to Justice in Sub-Saharan Africa: The Role of Traditional and Informal Justice Systems, London: Penal Reform International Rattray, R.S. (1969) Ashanti Law and Constitution, Oxford: Clarendon Press (first published 1929)

Swidler, A. (1986) 'Culture in Action: Symbols and Strategies', American Sociological Review 51: 273-86 